\title{
Load-Settlement Response of Square Footing on Geogrid Reinforced Layered Granular Beds
}

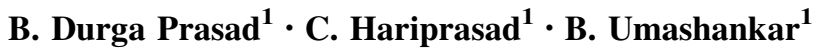

Received: 12 July 2016/Accepted: 15 September 2016/Published online: 7 November 2016

(C) Springer International Publishing Switzerland 2016

\begin{abstract}
Experimental studies were carried out to obtain the load-settlement response of a model square footing resting on unreinforced and reinforced granular beds. The response was obtained for two cases: (a) geogrid-reinforced sand layer, and (b) geogrid-reinforced layered system consisting of aggregate layer overlying a sand layer. The parameters considered in the experimental study include the thickness of the aggregate layer, the depth of geogrid reinforcement placed in sand layer and in aggregate layer, width of the reinforcement, and relative density of bed. Plate vibrator was used to compact uniform sand beds to relative densities equal to $50 \%$ and $70 \%$ inside large-size test chamber of dimensions equal to $1 \mathrm{~m} \times 1 \mathrm{~m} \times 1 \mathrm{~m}$ (in length, in width, and in depth). Load was applied on square footing using a $100 \mathrm{kN}$ capacity actuator in displacementcontrolled mode, and the improvement in the load carrying capacity of the footing resting on reinforced sand layer and layered system was quantified in terms of load improvement factors. In addition, the optimum embedment depth and width of reinforcements were proposed for various cases considered in the study. The optimum depth of reinforcement for the case of aggregate layer overlying sand layer decreased to 0.30 times the width of the footing from 0.45 times the width of the footing for sand only case.
\end{abstract}

B. Umashankar

buma@iith.ac.in

B. Durga Prasad

b.d.prasad2003@gmail.com

C. Hariprasad

hariprasadiith@gmail.com

1 Department of Civil Engineering, IIT Hyderabad, Kandi, Telangana 502285, India
Keywords Square footing - Geogrid - Sand bed · Aggregate layer · Load improvement factor

\section{Introduction}

Use of geosynthetics has revolutionized the field of ground improvement. Geosynthetic reinforcements in the form of geogrid, geotextile, geomembrane, and geocells are most commonly used to reinforce weak soil leading to improvement in the load-carrying capacity and reduction of settlement of structures supported on reinforced beds. The maximum benefit from inclusion of reinforcement is achieved when it is placed within the zone of influence of applied loading. Several researchers have conducted experiments to find the optimum depth of first layer of reinforcement when number of reinforcement layers were used [1-11].

Fragaszy and Lawton [1] conducted series of laboratory model tests to obtain the load-settlement response of rectangular footings resting on uniformly-graded sand. Bearing capacity ratio (BCR) was reported between 1.2 and 1.7 based on the relative density of the sand bed, and was found to be higher for dense sands compared to loose sands. Yetimoglu et al. [2] performed both experimental and numerical parametric studies to investigate the bearing capacity of rectangular footings on geogrid-reinforced sand. The test results showed that the optimum embedment depth of the reinforcement was equal to about 0.3 times the footing width for single-layer reinforced sand, whereas it was about 0.25 times the footing width for multi layered reinforced sand.

Adams and Collin [3] performed large-scale model tests on $0.3,0.46,0.61$, and $0.91 \mathrm{~m}$ wide square footings resting on multi layered geogrid reinforced soil foundations. The 
maximum improvement in bearing capacity of footing was achieved when the top layer of reinforcement was embedded within 0.25 times the size of the footing from the surface. Kumar and Walia [4] performed model tests on a square footing resting on a two-layer system with the top layer reinforced with geogrid. Thicknesses of the top and bottom layers were varied from 0.5 to $2.0 \mathrm{~m}$ and 2.0 to $3.5 \mathrm{~m}$, respectively. Based on the model test results, an equation was proposed to predict the ultimate bearing capacity of square and rectangular footings resting on reinforced layered soils. Chung and Cascante [5] performed experimental and numerical studies on square footing and recommended using 2-4 layers of reinforcement in the design of reinforced granular beds.

Boushehrian and Hataf [6] performed experimental and numerical studies to investigate the bearing capacity of model circular and ring footings on reinforced sand. Based on laboratory model tests and numerical analysis, the optimum depth of the top reinforcement layer was reported as 0.33-0.47 times the outer diameter of the footing for one to four layers of reinforcement. BCR was found to decrease when the top layer was placed beyond $0.4 B$ and the improvement was found to be insignificant beyond certain number of layers of reinforcement. Similar observations were also reported by Laman and Yildiz [7]. Basudhar et al. [8] studied the behavior of $30 \mathrm{~mm}$ diameter model circular footing resting on sand beds reinforced with geotextiles. Both experimental and numerical studies were performed with number of layers of reinforcement varying from 0 to 3 and relative density of sand bed varying from 45 to $84 \%$. They reported bearing capacity ratio improvement of about 4.5 times that of unreinforced case when the sand bed was reinforced with three layers of reinforcement. Zidan [9] conducted numerical study using finite element analysis to investigate the behavior of circular footing resting over reinforced sand. Results indicated that the depth of top layer plays an important role in the behavior of the reinforced soil, and reported that the optimum depth of top layer was equal to 0.19 times the diameter of the footing. Load improvement ratio for reinforced coarse sand was higher than that of reinforced fine and medium sand [10]. Load improvement ratio of about 3.2 was obtained for coarse sand reinforced with three layers of reinforcement corresponding to footing settlement equal to $0.5 \mathrm{~mm}$.

Studies indicate that the effectiveness of the reinforcement increased with the use of stiff geogrid reinforcement [11]. Ballast reinforced with geogrid of tensile strength equal to $45 \mathrm{kN} / \mathrm{m}$ showed a $50 \%$ increase in strength compared to that of ballast reinforced with geogrid of tensile strength equal to $30 \mathrm{kN} / \mathrm{m}$.

An extensive review of the literature indicated that studies on determination of the optimum depth of the reinforcement placed in aggregate layer overlying a sand layer were very limited. Accordingly, tests were performed in a large-size test chamber to determine the load-settlement behavior of square footing for different cases with footing resting on (a) unreinforced aggregate layer overlying sand layer (Case I), (b) single layer of reinforcement embedded in sand alone (Case II), and (c) single layer of reinforcement embedded in aggregate layer overlying sand (Case III). In addition, the optimum depth and width of the reinforcement were also proposed based on load-settlement response of model footing resting on layered beds.

\section{Materials and Characterization}

Locally available river sand and aggregates were used as granular beds during experimentation. The relevant properties of the materials were determined following ASTM standard test procedures. Figure 1 shows the grain-size distribution of sand. It was classified as poorly-graded sand (SP) according to the Unified Soil Classification System (USCS). Table 1 provides the physical properties of the sand used in the study. The maximum unit weight of sand was obtained from the vibratory compaction method. Figure 2 shows the morphology of the sand particles from scanning electron microscopy (SEM), and shape of the particles were found to be angular to sub angular. Locally available aggregates were used as strong granular layer that overlies sand layer, and the aggregates were found to be uniform in size ranging from 6.3 to $10 \mathrm{~mm}$.

The reinforcement consisted of a geogrid (make: NAUE-Secugrid 40/40) with aperture size equal to $30 \times 30 \mathrm{~mm}$ (Fig. 3). Table 2 gives the physical properties of the geogrid used in the study.

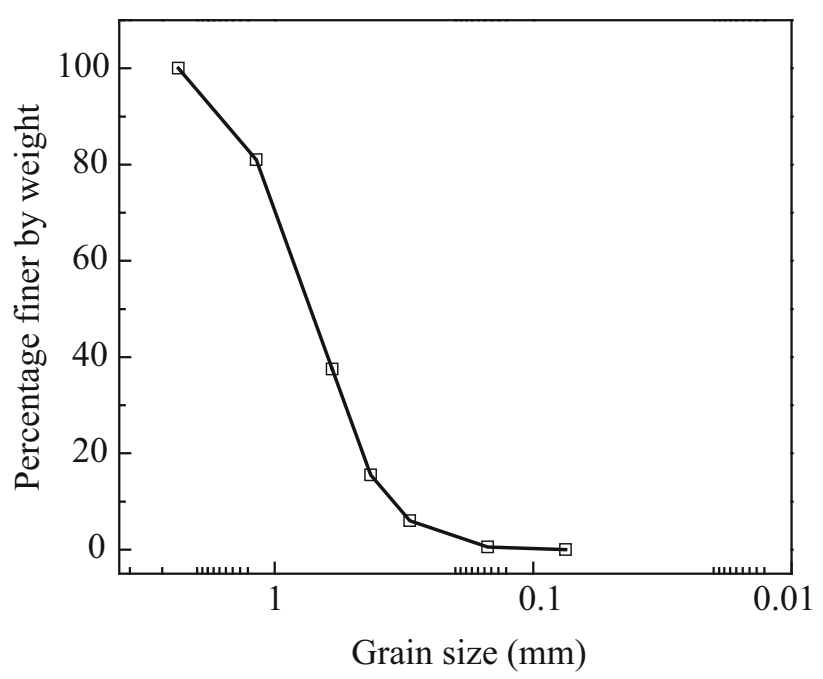

Fig. 1 Grain-size distribution curve of sand 
Table 1 Physical properties of sand used in the study

\begin{tabular}{lc}
\hline Property & Value \\
\hline$D_{10}(\mathrm{~mm})$ & 0.29 \\
$D_{30}(\mathrm{~mm})$ & 0.48 \\
$D_{60}(\mathrm{~mm})$ & 0.7 \\
Coefficient of curvature, $C_{\mathrm{c}}$ & 1.1 \\
Coefficient of uniformity, $C_{\mathrm{u}}$ & 2.4 \\
Specific gravity, $G_{\mathrm{s}}$ & 2.65 \\
Maximum dry unit weight $\left(\mathrm{kN} / \mathrm{m}^{3}\right)$ & 17.8 \\
Minimum dry unit weight $\left(\mathrm{kN} / \mathrm{m}^{3}\right)$ & 15.1 \\
\hline
\end{tabular}

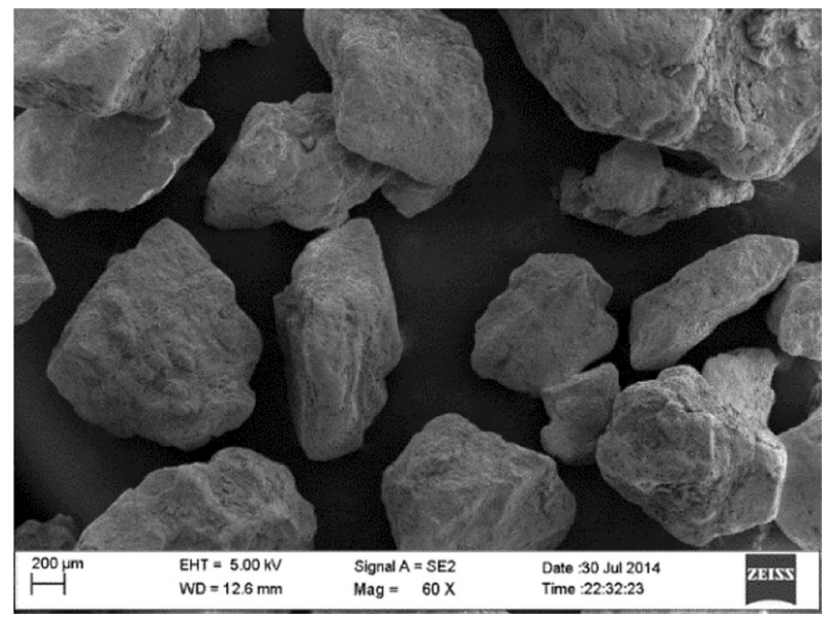

Fig. 2 Morphology of sand particles obtained from SEM at a magnification of $60 \mathrm{x}$

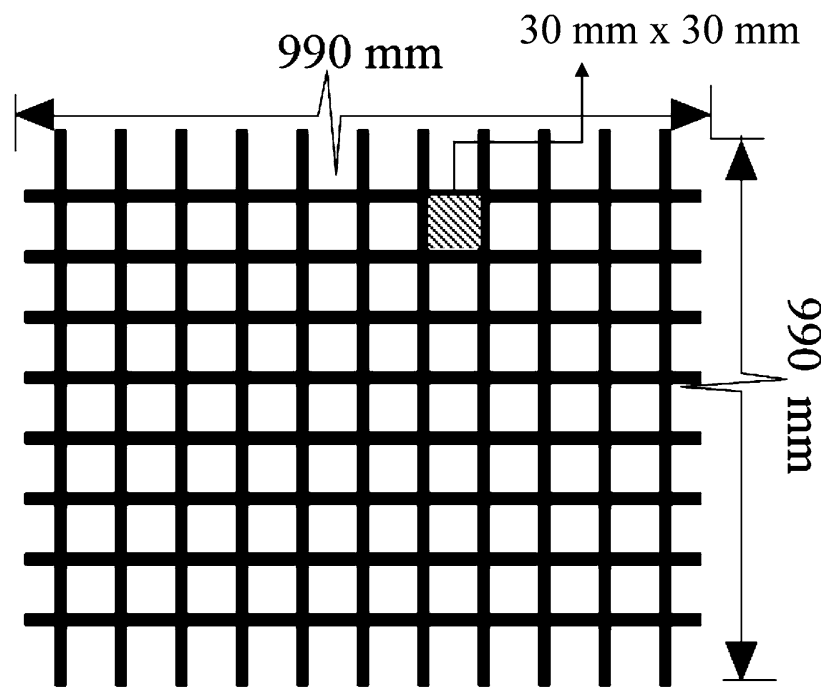

Fig. 3 Schematic diagram of geogrid reinforcement
Table 2 Properties of geogrid reinforcement

\begin{tabular}{ll}
\hline Property & Value \\
\hline Mass per unit area $\left(\mathrm{g} / \mathrm{m}^{2}\right)$ & 240 \\
Maximum tensile strength, $\mathrm{md} / \mathrm{cmd}(\mathrm{kN} / \mathrm{m})$ & $\geq 40 / \geq 40$ \\
Tensile strength at $2 \%$ elongation, $\mathrm{md} / \mathrm{cmd}(\mathrm{kN} / \mathrm{m})$ & $16 / 16$ \\
Tensile strength at $5 \%$ elongation, $m d / c m d(\mathrm{kN} / \mathrm{m})$ & $32 / 32$ \\
\hline
\end{tabular}

$m d$ machine direction, $c m d$ cross machine direction

\section{Experimental Studies}

A large-size test chamber of size equal to $1 \mathrm{~m} \times 1 \mathrm{~m}$ $\times 1 \mathrm{~m}$ was used to study the behavior of square footing resting on granular beds. The applied loads were resisted against a reaction frame of $100 \mathrm{kN}$ capacity, and the frame consisted of four columns supporting two horizontal beams (Fig. 4). The width and thickness of square footing were equal to 200 and $30 \mathrm{~mm}$, respectively. Load was applied in displacement-controlled mode on the loading plate through an actuator using a computer-controlled, servo-hydraulic actuator. The actuator was attached to the frame with a clearance height equal to $3.5 \mathrm{~m}$.

\section{Sample Preparation and Test Procedure}

The side walls of the test chamber were covered by double layer polythene sheets to reduce the boundary effects. Sand

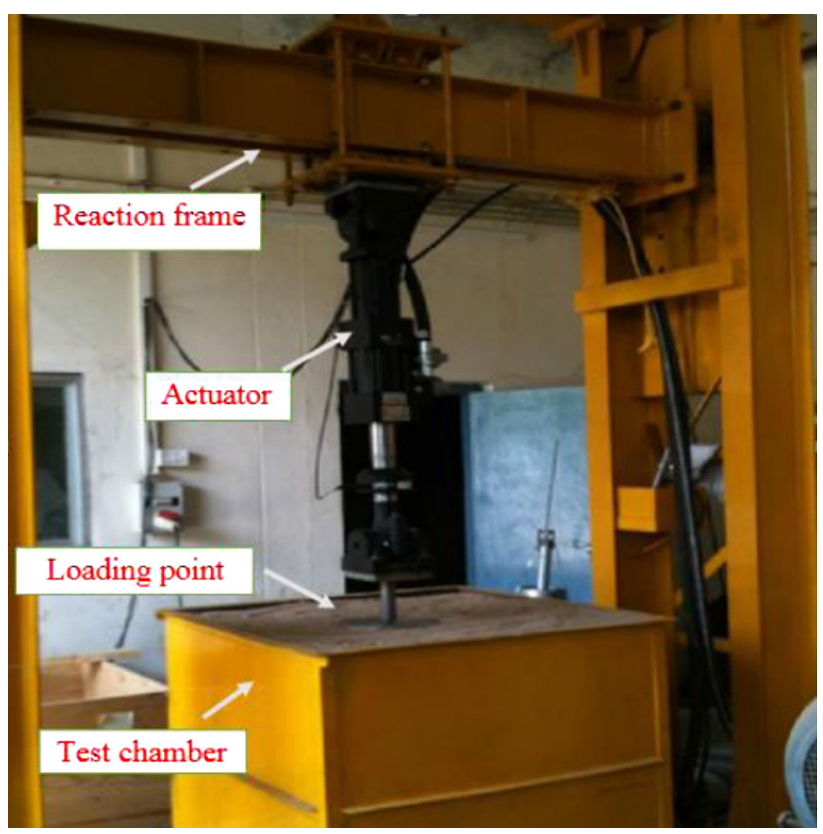

Fig. 4 Photograph of the test frame, test chamber, and actuator 
bed was compacted using a pneumatically-operated, impact-type piston vibrator, manufactured by NAVCO (Model: $B H-2$ IGO). The vibrator was connected to a pressure source through a pressure line, and a steel plate of dimensions equal to $300 \mathrm{~mm} \times 300 \mathrm{~mm} \times 10 \mathrm{~mm}$ (in length, width and thickness) was bolted to the bottom of the vibrator (Fig. 5). Sand beds were prepared in five $160 \mathrm{~mm}$ thick layers by traversing the vibrator over the sand bed. The pneumatic pressure inside the vibrator was adjusted to achieve sand beds of two target relative densities equal to 50 and $70 \%$. After preparation of the sand bed, aggregate was placed over the sand bed and the aggregate layer was compacted to a compacted dry unit weight equal to $13.8 \mathrm{kN} / \mathrm{m}^{3}$. Reinforcement was then placed at predetermined depths from the bottom of the footing.

The model square footing was placed on the prepared bed and plunger was used to connect the actuator to the footing plate. Provision was made at the center of the model footing plate to accommodate a ball bearing that facilitates application of loads on the footing. Load from the actuator was applied in displacement-controlled mode and the rate of displacement of footing was equal to $1 \mathrm{~mm} /$ min. Multi-Purpose Test ware (MPT) software records the loads and settlements from the load cell and LVDT sensors at every $10 \mathrm{~s}$ interval. After completion of the test, load and settlement readings were obtained directly from the software.

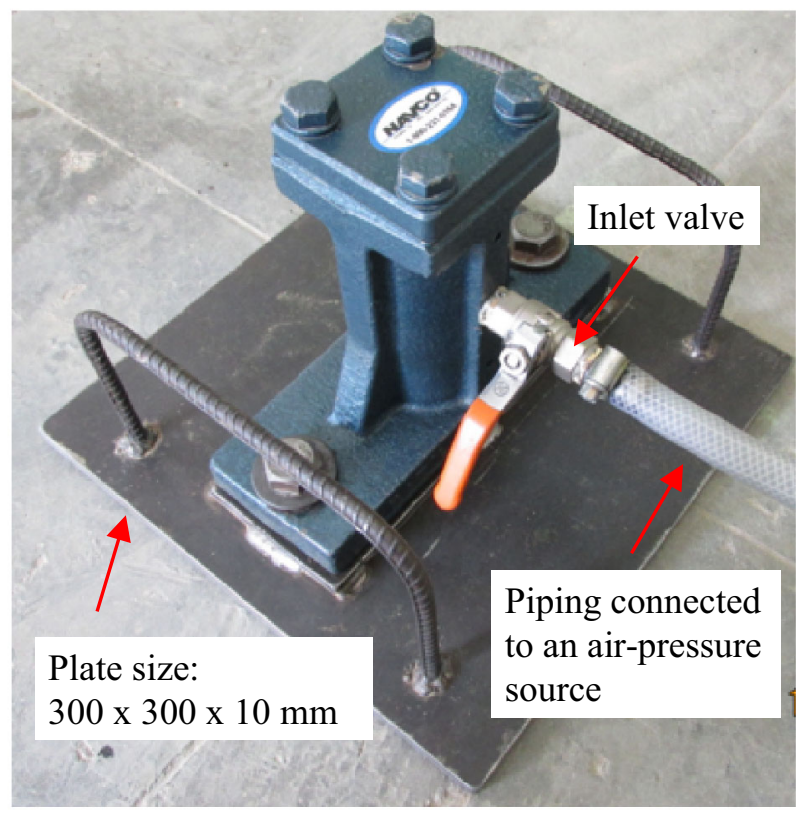

Fig. 5 Pneumatic vibrator used for compaction

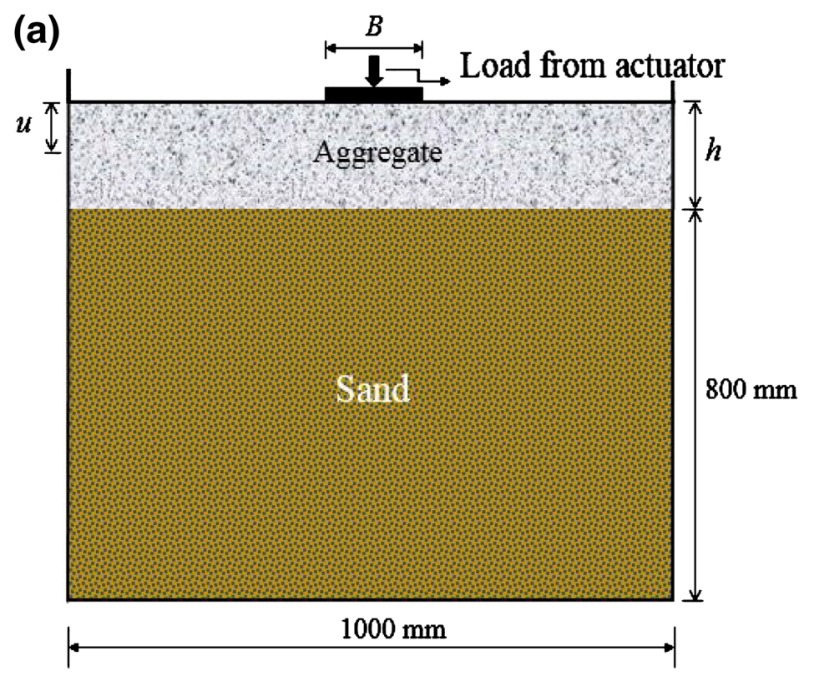

(b)

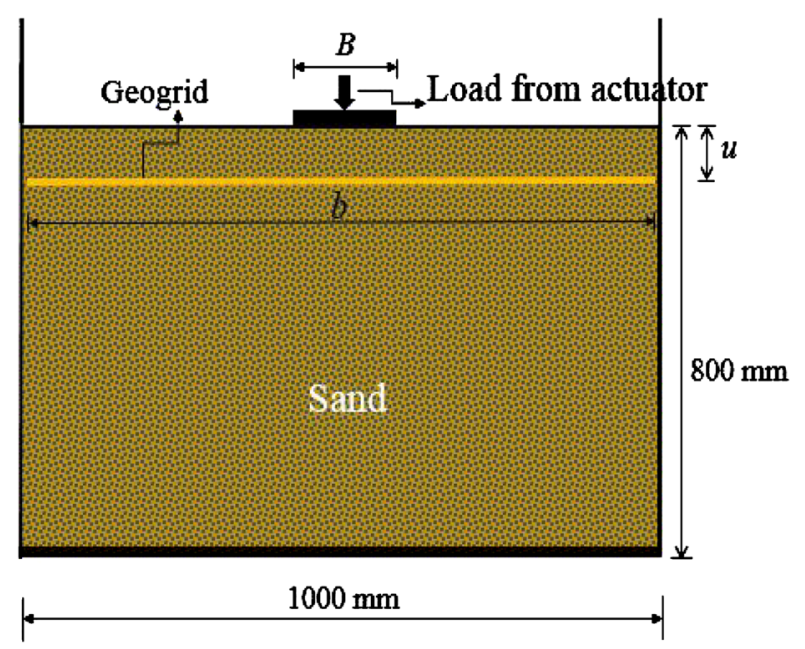

(c)

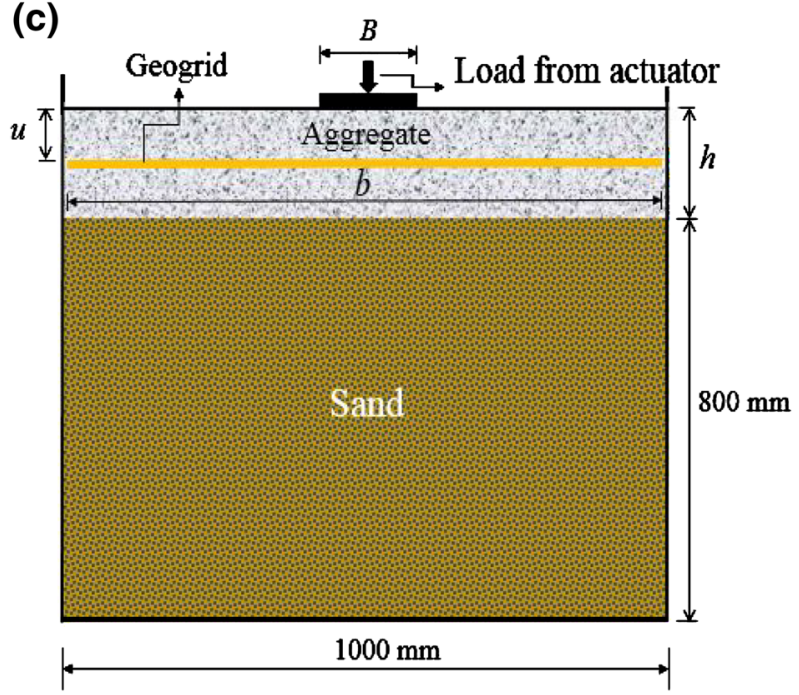

Fig. 6 Schematic showing a aggregate layer overlying sand (Case I), b reinforced sand bed (Case II), and c reinforced granular layer overlying sand (Case III) 


\section{Testing Program}

Figure 6 shows the schematic view of the test bed for unreinforced and reinforced cases of sand layer alone and aggregate layer overlying sand layer. The experimental studies were performed to study the influence of various test configurations on the load-settlement response of the footing. Table 3 provides the details of various test configurations considered in the study.

\section{Results and Discussion}

The improvement in the performance due to the provision of the geogrid and aggregate layer (reinforced and unreinforced) was quantified by using a non-dimensional parameter, load improvement factor $\left(I_{f}\right)$, defined as

$I_{f}=\frac{q_{\mathrm{r}}}{q_{0}}$

where, $I_{f}$ load improvement factor, $q_{\mathrm{r}}$ bearing pressure of the reinforced soil foundation at a given settlement, and $q_{0}$ bearing pressure of the unreinforced soil foundation at the same settlement.

\section{Unreinforced Aggregate Layer Overlying Sand Layer (Case I)}

Replacement or addition of a competent fill material over a weak material is one of the commonly adopted ground improvement techniques. Accordingly, the improvement in load-settlement response of an aggregate layer over a sand layer was studied. The relative density of sand layer was maintained as $70 \%$. The thickness of aggregate layer was varied as $0.1 B, 0.25 B$ and $0.5 B$ overlying sand (Test series$A$ ). Figure 7 presented the variation of bearing pressure with settlement ratio for different thicknesses of the aggregate layer. Bearing pressure increased with increase in the thickness of the aggregate layer. According to Umashankar et al. [12], the top stiff layers absorb significant portion of the load applied on the surface of footing, and similar observations were made in the present study. For instance, at a settlement ratio $(s / B)$ of $10 \%$, the bearing pressure increased by about $81 \%$ for the case of $100 \mathrm{~mm}$ thick aggregate layer overlying sand when compared with the unreinforced sand. Table 4 gives the load improvement factors with the settlement ratios for various thicknesses of aggregate layer overlying sand.

Table 3 Details of the test program used in the study

\begin{tabular}{|c|c|c|c|c|}
\hline \multirow[t]{2}{*}{ Test Series } & \multicolumn{4}{|c|}{ Parameters used in tests ${ }^{*}$} \\
\hline & $u / B$ & $b / B$ & $h / B$ & $D_{\mathrm{R}}(\%)$ \\
\hline \multirow[t]{3}{*}{$A$ (Effect of thickness aggregate layer overlying sand) } & - & - & 0.10 & 70 \\
\hline & - & - & 0.25 & 70 \\
\hline & - & - & 0.50 & 70 \\
\hline \multirow[t]{4}{*}{$B$ (Effect of depth of reinforcement in sand) } & 0.15 & 5 & - & 70 \\
\hline & 0.30 & 5 & - & 70 \\
\hline & 0.45 & 5 & - & 70 \\
\hline & 0.60 & 5 & - & 70 \\
\hline \multirow[t]{3}{*}{$C$ (Effect of width of reinforcement in sand) } & 0.45 & 3 & - & 70 \\
\hline & 0.45 & 4 & - & 70 \\
\hline & 0.45 & 5 & - & 70 \\
\hline \multirow[t]{2}{*}{$D$ (Effect of relative density of sand when reinforced) } & 0.45 & 4 & - & 50 \\
\hline & 0.45 & 4 & - & 70 \\
\hline \multirow[t]{3}{*}{$E$ (Effect of depth of reinforcement in aggregate layer overlying sand) } & 0.15 & 5 & 0.50 & 70 \\
\hline & 0.30 & 5 & 0.50 & 70 \\
\hline & 0.45 & 5 & 0.50 & 70 \\
\hline \multirow[t]{3}{*}{$F$ (Effect of width of reinforcement placed in aggregate layer overlying sand) } & 0.30 & 3 & 0.50 & 70 \\
\hline & 0.30 & 4 & 0.50 & 70 \\
\hline & 0.30 & 5 & 0.50 & 70 \\
\hline \multirow[t]{2}{*}{$G$ (Effect of relative density of sand underlying reinforced aggregate layer) } & 0.30 & 4 & 0.50 & 50 \\
\hline & 0.30 & 4 & 0.50 & 70 \\
\hline
\end{tabular}

* $u$ is depth of reinforcement; $b$ is width of reinforcement; $h$ is thickness of aggregate layer; $B$ is width of the footing; $D_{R}$ is relative density of sand 


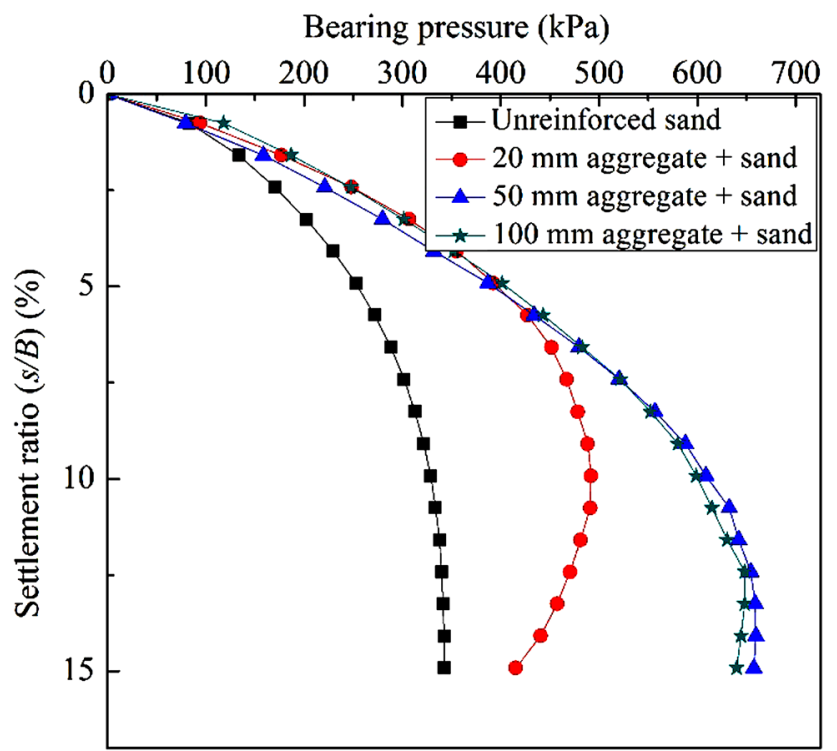

Fig. 7 Variation of bearing pressure with settlement ratio $(s / B)$ for aggregate overlying sand (Test series- $A$ )

Table 4 Load improvement factors for different thicknesses of aggregate layer overlying sand

\begin{tabular}{lll}
\hline $\begin{array}{l}\text { Thickness of aggregate layer, } \mathrm{h}, \\
\text { overlying sand layer }\end{array}$ & $\begin{array}{l}\text { Settlement } \\
\text { ratio }(\mathrm{s} / B)(\%)\end{array}$ & $\begin{array}{l}\text { Load } \\
\text { improvement } \\
\text { factor }\left(I_{f}\right)\end{array}$ \\
\hline $0.1 B(=20 \mathrm{~mm})$ & 5.0 & 1.56 \\
$0.25 B(=50 \mathrm{~mm})$ & 7.5 & 1.73 \\
$0.5 B(=100 \mathrm{~mm})$ & 10.0 & 1.83 \\
\hline
\end{tabular}

\section{Geogrid-Reinforced Sand Layer (Case II)}

\section{Effect of Depth of Reinforcement}

The geogrid reinforcement embedded in sand layer improves the load-settlement response of the footing resting on it. Single layer of geogrid reinforcement was used to reinforce the sand layer and the effect of embedment depth of reinforcement on the load-settlement behavior of the footing was studied. The depth of the reinforcement, $u$, was varied as $0.15,0.3,0.45$ and 0.6 times the width of the footing, $B$, to study the optimum depth of reinforcement (Test series- $B$ ). Figure 8 presented the variation of bearing pressure with settlement ratio for various reinforcement depth ratios. It can be concluded that as the depth ratio, $u$ / $B$, increases from 0.15 to 0.3 to 0.45 , the bearing pressure also increases for a given settlement of the footing. However, it was observed that for further increase in depth ratio to 0.6 , the bearing pressure on the footing decreases. For a settlement ratio equal to $10 \%$, as the depth of the geogrid was varied as $0.15 B, 0.3 B, 0.45 B$ and $0.6 B$ the percentage

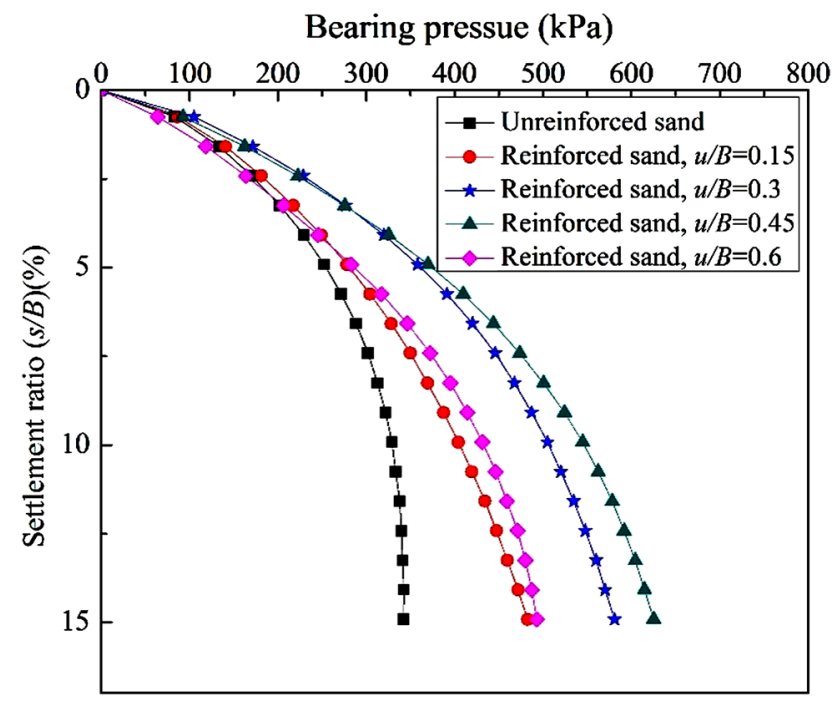

Fig. 8 Variation of bearing pressure with settlement ratio $(s / B)$ for reinforced sand (Test series- $B$ )

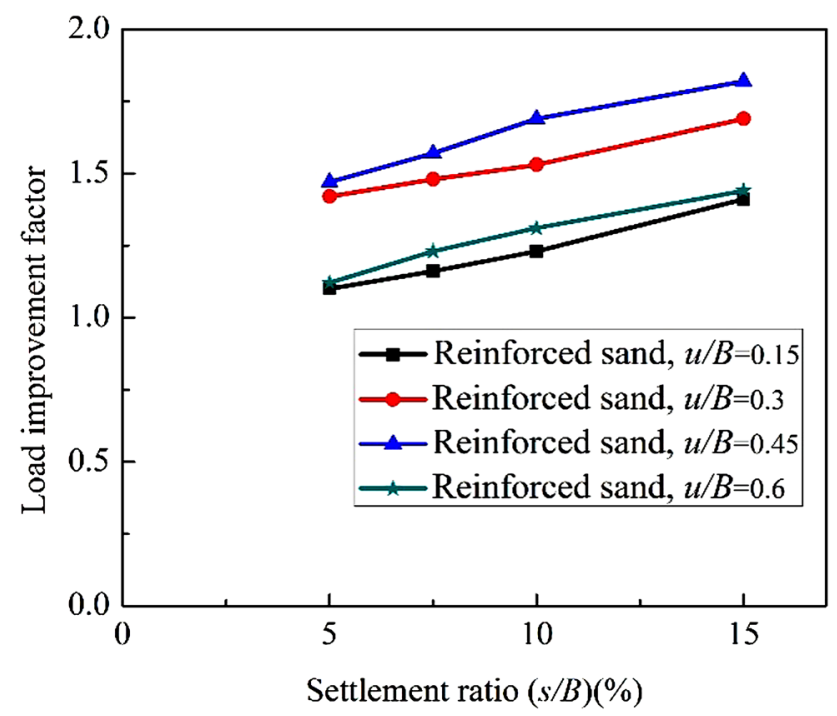

Fig. 9 Variation of load improvement factor with settlement ratio $(s /$ $B$ ) for reinforced sand (Test series- $B$ )

increase in the bearing pressure with respect to unreinforced sand was found to be 23, 54, 66 and $32 \%$, respectively. Figure 9 presented the variation of load improvement factor with settlement ratio for Test series$B$. For a settlement ratio equal to $10 \%$, the load improvement factor increased by $8 \%$ when the geogrid reinforcement was placed at $u=0.45 B$ compared to that placed at $u=0.3 B$. However, the load improvement factor decreased by $21 \%$ when the depth of reinforcement was further increased to $0.6 B$ from $0.45 B$, indicating that the geogrid reinforcement placed beyond $0.45 B$ was not effective in improving the load carrying capacity of the footing. Hence, the optimum depth of the geogrid 
reinforcement was found to be $0.45 B$ when the single layer of reinforcement was placed in the sand layer.

\section{Effect of Width of Reinforcement on Load-Settlement Response}

Experimental results in Test series- $B$ indicate that the optimum depth of the reinforcement in sand layer system was equal to $0.45 B$ (refer to Fig. 8). In this series of experiments, the width of the reinforcement was maintained as equal to the width of the test chamber in both the directions (i.e., equal to five times the width of the footing). To study the effect of width of the reinforcement on loadsettlement behavior of the footing, tests were performed for different widths of reinforcement equal to $3 B, 4 B$, and $5 B$, maintaining the depth of reinforcement at the optimum depth (equal to $0.45 B$ ). Figure 10 presented the variation of bearing pressure with settlement ratio for different widths of geogrid placed in sand. Results indicate that as the width of the reinforcement increases from $3 B$ to $5 B$, there was increase in the bearing pressure. For instance, at a settlement ratio of $(s / B)$ equal to $10 \%$, the bearing pressure increased by about 3 and $10 \%$ as the width of the reinforcement increases from $3 B$ to $4 B$ and from $3 B$ to $5 B$, respectively. Hence, the width of reinforcement for subsequent testing was taken as four times the width of the footing to avoid boundary effects. For the range of settlements of model footing considered in the study, no failure was observed for the reinforced layered system. Latha and Somwanshi [13] also concluded that the optimum width of the reinforcement was about four times width of the footing for a square footing resting on a reinforced foundation soil.

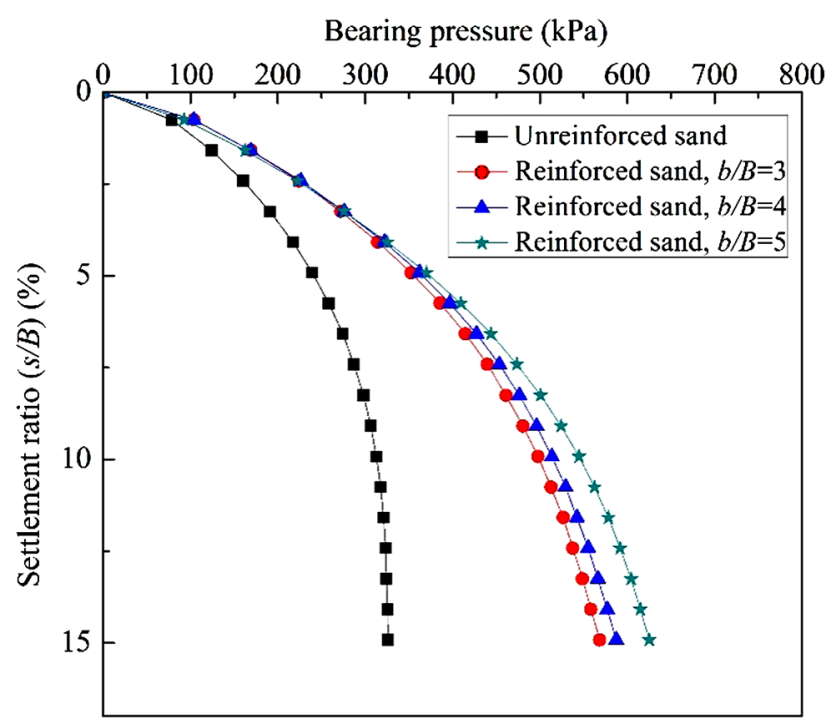

Fig. 10 Variation of bearing pressure with settlement ratio $(s / B)$ for reinforced sand at optimum depth (Test series- $C$ )
Effect of Relative Density of Sand on Load-Settlement Response

Tests were performed by preparing the reinforced sand beds at two different relative densities, equal to 50 and $70 \%$. The geogrid reinforcement was placed at an optimum depth of $0.45 B$ and the width of the reinforcement was maintained as $4 B$. Figure 11 presented the variation of bearing pressure under the footing with settlement ratio for the two relative densities. For a settlement ratio $(s / B)$ equal to $10 \%$, the bearing capacity of the reinforced sand increased by $37 \%$ compared to that of unreinforced sand corresponding to $50 \%$ relative density of sand bed. Similarly, for sand bed prepared with a relative density of $70 \%$, an increase of $57 \%$ in the bearing pressure of the reinforced sand was noticed compared with unreinforced sand. This shows that the improvement in load carrying capacity of footing on reinforced sand was higher for dense sand beds $\left(D_{R}=70 \%\right)$ than that of less dense beds $\left(D_{R}=50 \%\right)$. Figure 12 presented the variation of load improvement factor with settlement ratio. Load improvement factor increased by $21 \%$ when the relative density of sand increased from 50 to $70 \%$ corresponding to a settlement ratio equal to $10 \%$.

\section{Geogrid-Reinforced Aggregate Layer Overlying Sand (Case III)}

\section{Effect of Depth of Reinforcement}

Reinforcement can be used to reinforce the aggregate layer to improve the load carrying capacity of the layered beds. In such cases, it is essential to determine the optimum depth of the reinforcement in the aggregate layer. In this

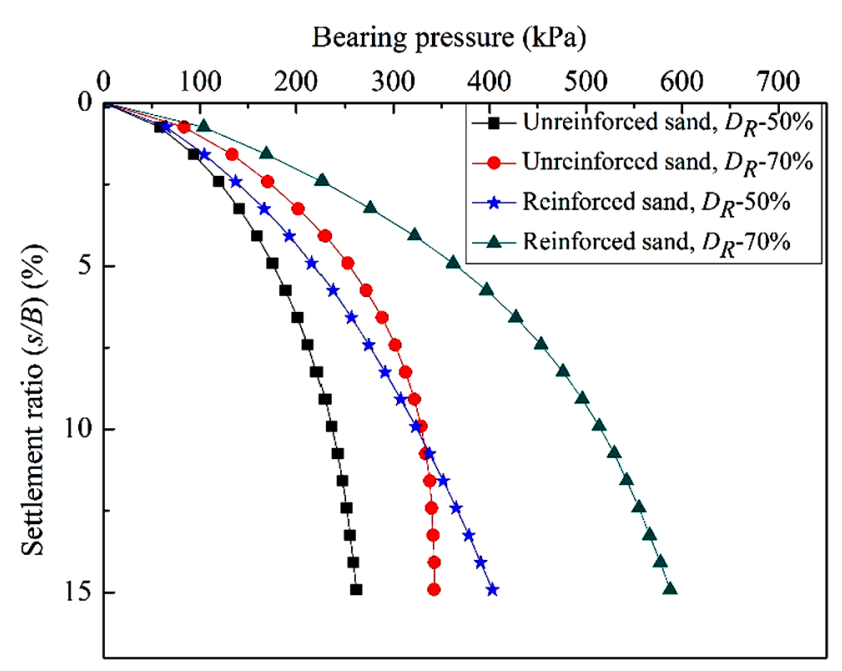

Fig. 11 Variation of bearing pressure with settlement ratio $(s / B)$ for sand (Test series- $D$ ) 


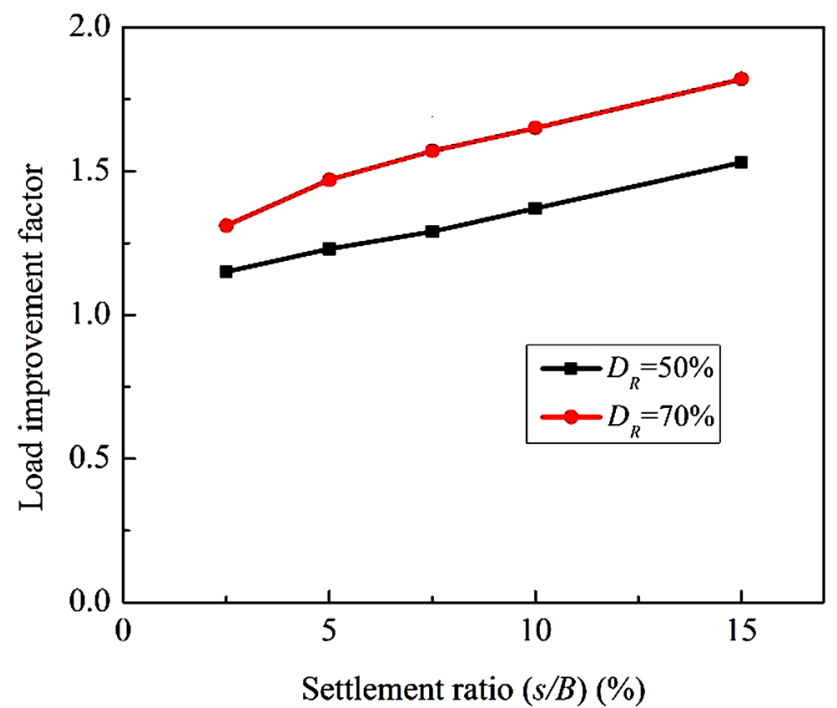

Fig. 12 Variation of load improvement factor with settlement ratio $(s / B)($ Test series- $D)$

study, the depth of reinforcement in the aggregate layer was varied as $0.15,0.3$ and 0.45 times the width of the footing to determine the optimum depth of reinforcement embedment (Test series- $E$ ). Figure 13 presented the variation of bearing pressure with settlement ratio for different depths of geogrid in the aggregate layer overlying sand. It can be inferred that as the depth ratio $(u / B)$ increases from 0.15 to 0.3 , the bearing pressure also increases. However, further increase in the depth ratio $(u / B)$ resulted in decrease in the bearing pressure. For instance, the percentage increase in the bearing pressure was found to be 16, 27 and $6 \%$ for the depth of the geogrid in the aggregate layer equal to $0.15 B, 0.3 B$ and $0.45 B$, respectively, corresponding to settlement ratio equal to $10 \%$. Figure 14 shows the

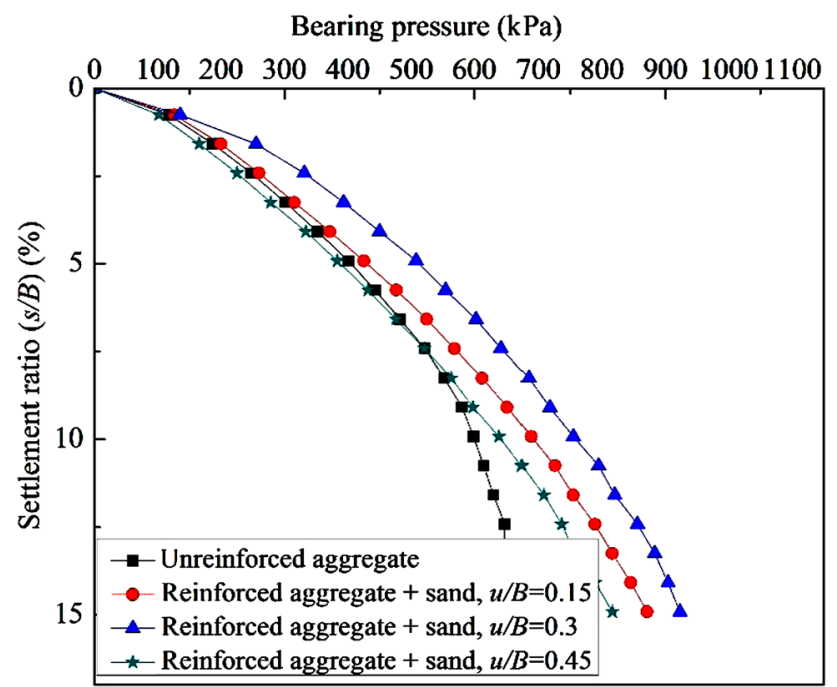

Fig. 13 Variation of bearing pressure with settlement ratio $(s / B)$ for reinforced aggregate layer (Test series- $E$ ) variation of load improvement factor with settlement ratio for Test series- $E$. The load improvement factors are given with respect to both unreinforced aggregate layer overlying sand and unreinforced sand. For a settlement ratio equal to $10 \%$, an increase of $9.5 \%$ in the load improvement factor was noticed when the geogrid was placed at $u=0.3 B$ compared with the geogrid placed at $u=0.15 B$. The corresponding increase in load improvement factor determined with respect to unreinforced sand was found to be $9.5 \%$. When the geogrid was placed at $u=0.45 B$, there was a decrease of $16 \%$ in the load improvement factor compared with the geogrid placed at $u=0.3 B$ for a settlement ratio of $10 \%$, indicating that the geogrid placed at a depth beyond $0.3 B$ in the aggregate layer was not effective. The optimum depth of single layer of geogrid reinforcement in the aggregate layer was found to be equal to $0.3 B$. The optimum depth of geogrid in aggregate layer overlying sand was less than that for sand alone because the applied stress on layered soil system was confined to the top stiff layer (aggregate layer).

\section{Effect of Width of Reinforcement}

The experimental results in Test series- $E$ indicate that the optimum depth of the reinforcement in aggregate was equal to $0.3 B$ (refer to Fig. 14). The width of the reinforcement for all the experiments in the Test series- $E$ was maintained the same as the tank size (i.e., equal to five times the width of the footing). To determine the effect of the width of the reinforcement on the load-settlement behavior of the footing, Test series- $F$ was designed. Geogrid reinforcement was placed at the optimum depth determined from the Test series- $E$, and the width of the reinforcement was varied as $3 B$ and $4 B$. Figure 15 presented the variation of bearing

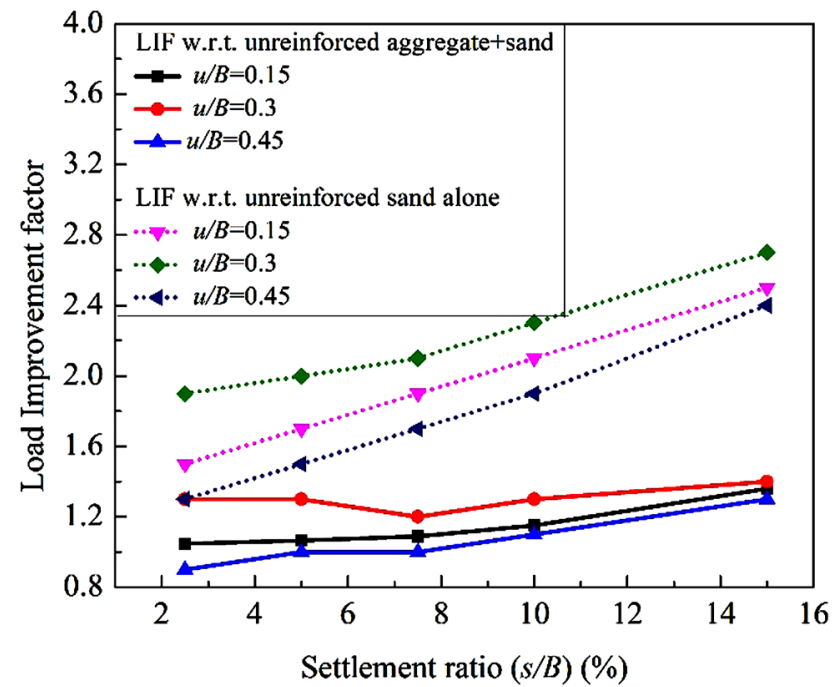

Fig. 14 Variation of load improvement factor with settlement ratio $(s / B)$ for reinforced aggregate layer overlying sand (Test series- $E$ ) 
pressure with settlement ratio for different widths of geogrid in aggregate layer. As the width of the reinforcement increases, the bearing pressure was found to increase at a given settlement ratio of the footing. For instance, corresponding to settlement ratio equal to $10 \%$, the bearing pressure increased by $7 \%$ and $11 \%$ as the width of the reinforcement increases from $3 B$ to $4 B$ and from $3 B$ to $5 B$, respectively. The width of reinforcement for subsequent testing was taken as four times the width of the footing to avoid boundary effects.

\section{Effect of Relative Density on Load-Settlement Response}

Similar to the case of sand, tests were performed on reinforced layered granular beds with compacted aggregate

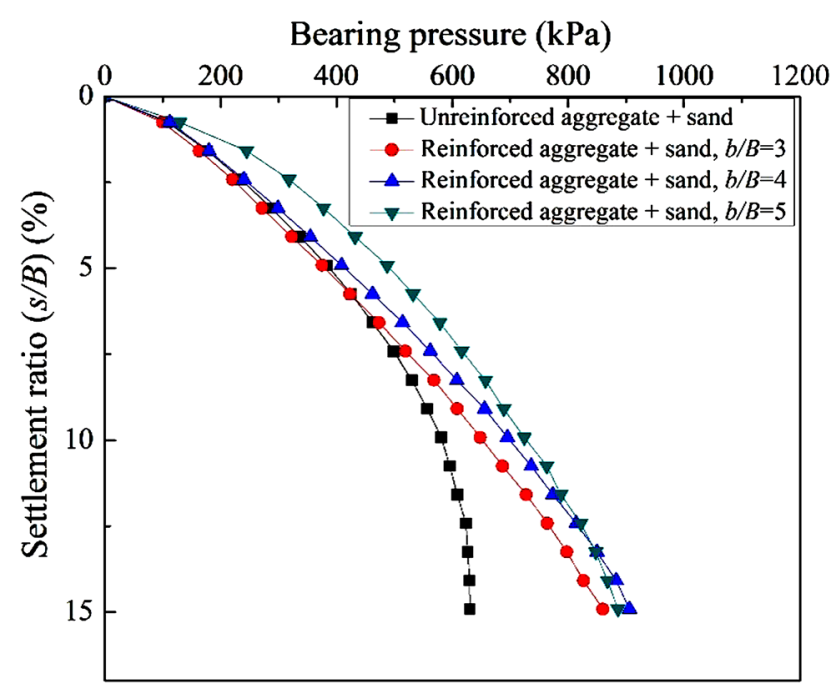

Fig. 15 Variation of bearing pressure with settlement ratio $(s / B)$ for reinforced aggregate (Test series- $F$ )

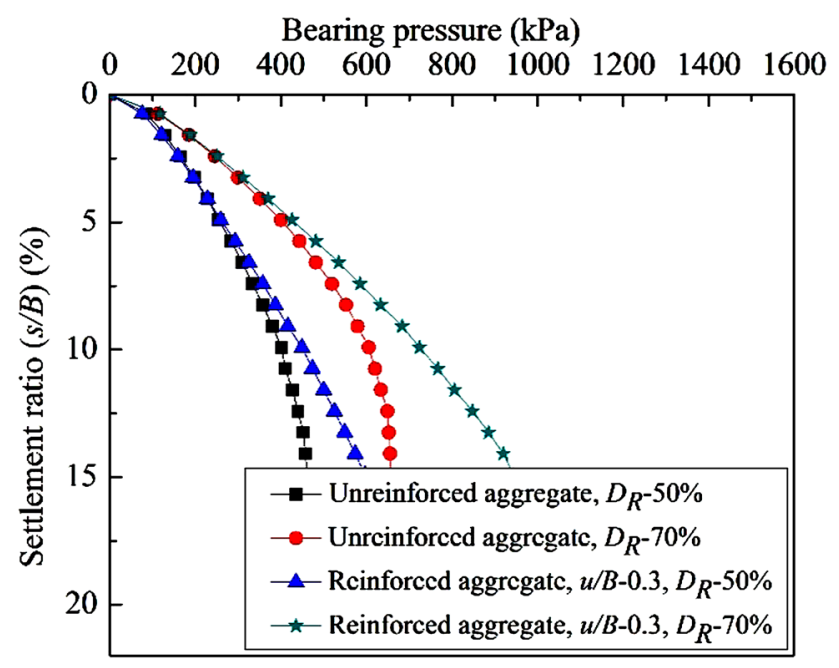

Fig. 16 Variation of bearing pressure with settlement ratio $(s / B)$ for aggregate layer overlying sand (Test series- $G$ )

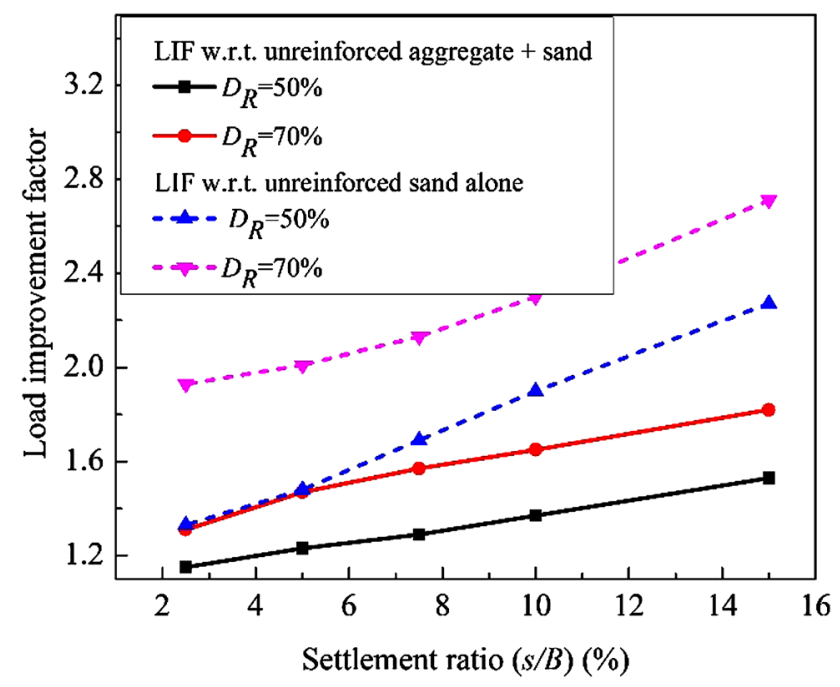

Fig. 17 Variation of load improvement factor with settlement ratio $(s / B)$ due to reinforced aggregate layer over sand (Test series- $G$ )

layer overlying sand of two different relative densities equal to $50 \%$ and $70 \%$. The geogrid reinforcement was placed at optimum depth of $0.3 B$ and the width of the reinforcement was maintained as $4 B$. The thickness of the aggregate layer was taken as $100 \mathrm{~mm}(=0.5 B)$. Figure 16 presented the variation of bearing pressure with settlement ratio for two relative densities of sand underlying aggregate layer. For sand bed with $50 \%$ relative density, the bearing pressure of the reinforced layered system increased by $13 \%$ compared to unreinforced layered system corresponding to settlement ratio $(s / B)$ equal to $10 \%$. Similarly, for aggregate layer over sand prepared with a relative density of $70 \%$, the corresponding increase in the bearing pressure was found to be $21 \%$. The increase was higher for reinforced aggregate layer on dense sand bed compared to that on relatively less dense sand bed. However, the improvement was not significant compared to that of sand alone. Figure 17 presented the variation of load improvement factor with the settlement ratio. For a settlement ratio equal to $10 \%$, the load improvement factor increased by $12 \%$ when the relative density of the bed increases from 50 to $70 \%$. The corresponding increase in load improvement factor determined with respect to unreinforced sand was found to be $21 \%$.

\section{Conclusions}

A series of experiments were conducted in large-size test chamber to study the load-settlement response of model square footing on unreinforced and reinforced aggregate layer overlying sand. The following conclusions can be drawn from the study. 
(1) The bearing pressure increased with the thickness of aggregate overlying the sand layer. For instance, at a settlement ratio equal to $10 \%$, the bearing pressure was found to increase by $81 \%$ due to $100 \mathrm{~mm}$ thick aggregate layer overlying sand. $100 \mathrm{~mm}$ thick aggregate layer corresponds to 0.5 times the size of footing.

(2) The optimum depth of geogrid reinforcement placed in sand alone was found to be 0.45 times the width of the footing. When the reinforcement was placed at the optimum depth, the bearing pressure was found to increase by $66 \%$ compared to the unreinforced case.

(3) For the case of reinforced aggregate layer overlying sand, the optimum depth of the reinforcement was found to be 0.3 times the width of the footing. When the reinforcement was placed in aggregate layer at this optimum depth, the bearing pressure was found to be increase by $27 \%$ compared to the unreinforced aggregate layer overlying sand.

(4) The load improvement factors were proposed for various cases - aggregate layer overlying sand (Case I), reinforced sand alone (Case II), and reinforced aggregate layer overlying sand (Case III). The load improvement factors ranged from 1.3 to $1.9,1.1$ to 1.8 , and 1.3 to 2.7 for the three cases, respectively, corresponding to footing settlement ratios ranging from 5 to $15 \%$.

\section{References}

1. Fragaszy RJ, Lawton E (1984) Bearing capacity of reinforced sand subgrades. J Geotech Eng ASCE 110(10):1500-1507
2. Yetimoglu T, Wu JTH, Saglamer A (1994) Bearing capacity of rectangular footings on geogrid-reinforced sand. J Geotech Eng ASCE 120(12):2083-2099

3. Adams MT, Collin JG (1997) Large model spread footing load tests on geosynthetic reinforced soil foundations. J Geotech Geoenviron Eng, ASCE 123(1):66-72

4. Kumar A, Walia BS (2006) Bearing capacity of square footings on reinforced layered soil. Geotech Geol Eng 24:1001-1008

5. Chung W, Cascante G (2007) Experimental and numerical study on soil-reinforcement effects on the low-strain stiffness and bearing capacity of shallow foundations. Geotech Geol Eng 25:265-281

6. Boushehrian JH, Hataf N (2003) Experimental and numerical investigation of the bearing capacity of model circular and ring footings on reinforced sand. Geotext Geomembr 21(4):241-256

7. Laman M, Yildiz A (2003) Model studies of ring foundations on geogrid-reinforced sand. Geosynth Int 10(5):142-152

8. Basudhar PK, Saha S, Deb K (2007) Circular footings resting on geotextile-reinforced sand bed. Geotext Geomembr 25:377-384

9. Zidan AF (2012) Numerical study of behavior of circular footing on geogrid-reinforced sand under static and dynamic loading. Geotech Geol Eng 30:499-510

10. Phanikumar BR, Prasad R, Singh A (2008) Compressive load response of geogrid-reinforced fine, medium and coarse sands. Geotext Geomembr 27(3):183-186

11. Brown SF, Kwan J, Thom NH (2007) Identifying the key parameters that influence geogrid reinforcement of railway ballast. Geotext Geomembr 25(6):326-335

12. Umashankar B, Hariprasad C, Kumar GT (2015) Compaction quality control of pavement layers using LWD. J Mater Civ Eng ASCE 28(2):1-9

13. Latha GM, Somwanshi A (2009) Bearing capacity of square footings on geosynthetic reinforced sand. Geotext Geomembr 27:281-294 